\title{
Comparison of the pressure time product during synchronous intermittent mandatory ventilation and continuous positive airway pressure
}

\author{
T Manczur, A Greenough, G F Rafferty
}

\begin{abstract}
Objective-To compare the effect of continuous positive airway pressure (CPAP) with synchronous intermittent mandatory ventilation (SIMV) during weaning, by measurement of the pressure time product (PTP). The PTP is an estimate of the metabolic work or oxygen consumption of the respiratory muscles.

Patients-Forty children, median age 14 months (range 1 month to 17 years) were studied immediately prior to extubation. Methods-The PTP, derived from airway pressure changes, was measured while the child received SIMV (with or without pressure support) and then CPAP. A pneumotachograph was placed between the endotracheal tube and ventilator circuit. Its flow signal was used to indicate the beginning and end of inspiration. Airway pressure was measured from the pneumotachograph and the area subtended by the pressure curve (PTP) calculated using a modified Labview programme.

Results-The median PTP was significantly lower on SIMV $\left(17.1 \mathrm{~cm} \mathrm{H} \mathrm{H}_{2} \mathrm{O} / \mathrm{sec} /\right.$ min, range 0.4 to 60.5$)$ compared to on CPAP $\left(32.6 \mathrm{~cm} \mathrm{H}_{2} \mathrm{O} / \mathrm{sec} / \mathrm{min}\right.$, range 0.1 to $116.7), \mathrm{p}<0.001$.

Conclusion-These results suggest SIMV, rather than CPAP, may be the more efficacious weaning mode in children, and that the time spent on CPAP during weaning should be minimised.

(Arch Dis Child 2000;83:265-267)
\end{abstract}

Keywords: extubation; reintubation; ventilation

Weaning failure, defined as the need for reintubation, is common in children, affecting between 15 and $20 \%$ of ventilated children. ${ }^{12}$ Adults who fail extubation, compared to those who are successfully weaned, are seven times more likely to die and 30 times more likely to spend more than 14 days in intensive care after extubation. ${ }^{3}$ Those data $^{3}$ emphasise the importance of identifying the most efficacious weaning technique. A recent survey of current practice in UK paediatric intensive care units (PICUs) highlighted that a variety of ventilatory modes were used during weaning. ${ }^{4}$ This may reflect the lack of randomised trials and physiological investigations to determine the relative efficacy of the techniques in children. The aim of this study was to compare the effect of continuous positive airway pressure (CPAP) and synchronous intermittent mandatory ventilation (SIMV) during weaning by measurement of the pressure time product (PTP). The PTP is a measure of the mechanical work of breathing and parallels the metabolic work or oxygen consumption of the respiratory muscles. ${ }^{5}$ It has been shown to differ significantly when measured in adults on different forms of respiratory support during weaning. ${ }^{5}$

\section{Methods}

Children were eligible for this study if they had been ventilated for at least 24 hours and the clinician in charge considered that they would be ready to extubate within the next few hours. Respiratory measurements were performed once informed written parental consent was obtained. The children were initially studied while receiving SIMV (with or without pressure support). Respiratory measurements on SIMV were only made 30 minutes after any nursing procedure, for example suction or physiotherapy. They were then studied at the end of a period of 30 minutes on CPAP. The CPAP was administered at the same magnitude as the positive end expiratory pressure level during assisted ventilation.

A pneumotachograph (series 4500, Hans Rudolph Inc, Kansas City MI, USA) was placed between the ventilator circuit and endotracheal tube. The pneumotachograph was attached to a differential pressure transducer (VDP45 +/-02.5 $\mathrm{cm} \mathrm{H}_{2} \mathrm{O}$, Validyne, Northridge CA, USA). Airway pressure was measured from a side arm on the pneumotachograph using a differential pressure transducer (Validyne MP45-1). The signals from the pressure transducers were amplified (Validyne CD 280 carrier amplifier) and displayed in real time on a laptop computer (Toshiba, Satellite $230 \mathrm{CX}$ ) running a customised Labview programme (version 4.0, National Instruments, Austin TX, USA) with analogue to digital sampling at $100 \mathrm{~Hz}$ (16 bit DAQ card AL-16XE-50, National Instruments). The flow signal from the pneumotachograph was integrated to give volume by the Labview programme.

Three separate one minute records were made during both SIMV and CPAP. Recordings were only made on CPAP after the child had stabilised on the new ventilatory mode. From each recording, the first period of regular breathing containing at least five breaths was identified. For each breath, the beginning and end of inspiration was determined from the flow signal (that is points of zero airflow). From 


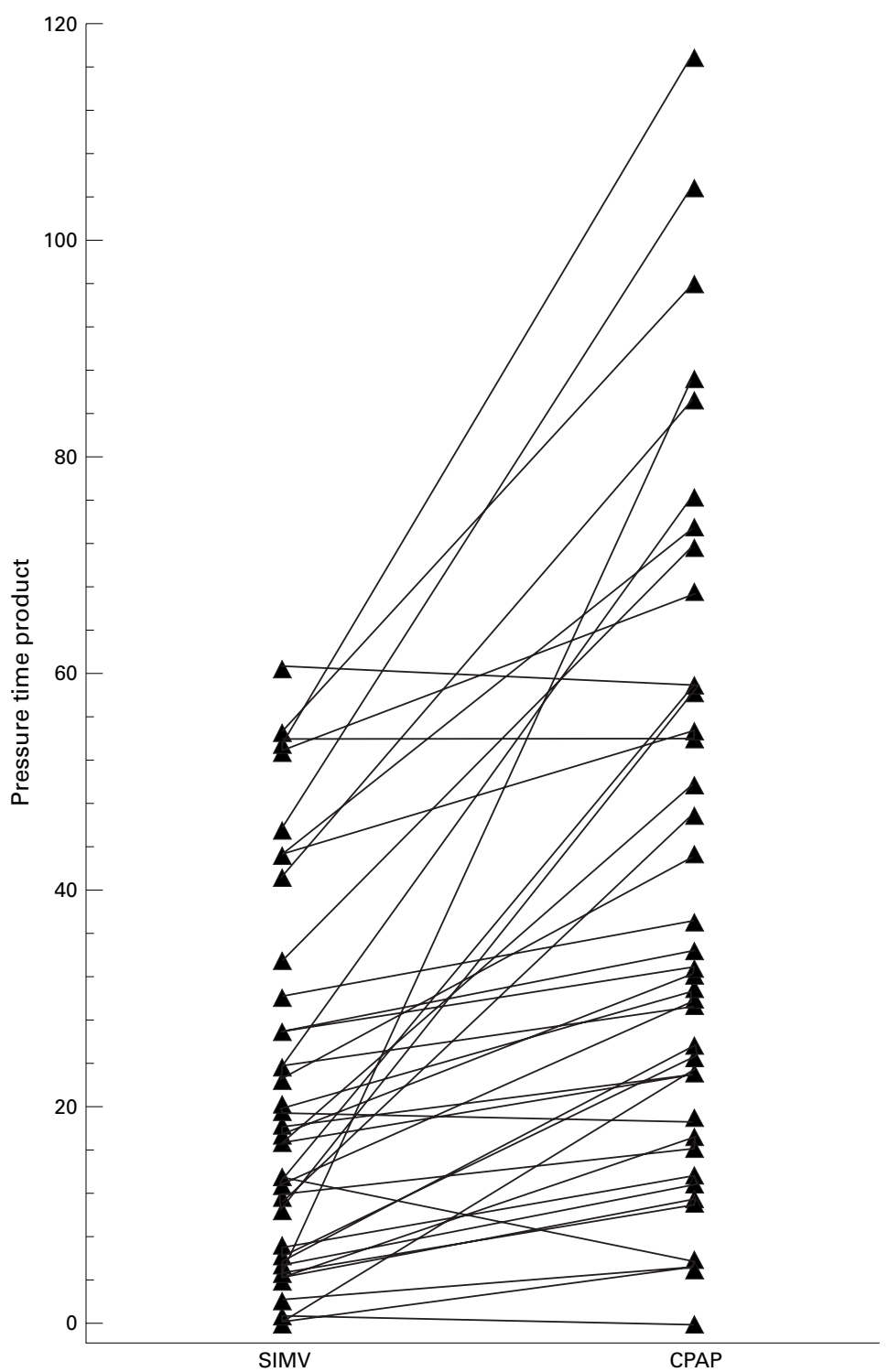

Figure 1 Comparison of the PTP ( $\mathrm{cm} \mathrm{H} \mathrm{H}_{2} \mathrm{O} / \mathrm{sec} / \mathrm{min}$ ) on SIMV and CPAP. Individual data are shown with each individual's results demonstrated by linked data points.

the recording of pressure against time, the PTP was calculated as the area under the pressure curve using the Labview programme. An individual's results were given by the mean of the breaths analysed on the relevant weaning mode.

\section{Statistical analysis}

Differences were assessed for statistical significance using the paired Wilcoxon rank sum test.

\section{PATIENTS}

Forty children, median age 14 months (range 1 month to 17 years) were studied. Fifteen were studied post-hepatic transplantation, six had intra-abdominal pathology, 14 intracranial abnormalities, and five primary respiratory disorders. All the children had followed the standard policies, that is during the weaning process they received SIMV with or without pressure support. At the time of study, their median SIMV rate was 11 , range 5 to 30 beats per minute. Sedation had been stopped once the clinician in charge felt the child was ready to wean. Throughout the weaning process, arterial blood gases were checked regularly and ventilatory settings altered to keep the gases within a predetermined range (arterial oxygen pressure 9 to $11 \mathrm{kPa}, \mathrm{pH} 7.3$ to 7.4 ). During weaning, patients were continuously monitored using oxygen saturation monitoring and the inspired oxygen concentration altered to keep the oxygen saturation at least $88 \%$. No child during the measurements required an alteration to his or her inspired oxygen concentration. This study was approved by the Research Ethics Committee of the King's Healthcare NHS Trust.

\section{RESULTS}

The median PTP was significantly lower when the children were supported on SIMV (17.1 $\mathrm{cm} \mathrm{H}_{2} \mathrm{O} / \mathrm{sec} / \mathrm{min}$, range 0.4 to 60.5 ) compared with on CPAP (median $32.6 \mathrm{~cm} \mathrm{H} \mathrm{H}_{2} \mathrm{O} / \mathrm{sec} / \mathrm{min}$, range 0.1 to 116.7 ), $\mathrm{p}<0.001$ (fig 1). Subgroup analysis demonstrated that the median PTP was lower on SIMV compared to on CPAP in children with intra-abdominal pathology $(p<0.01)$ and intracranial abnormalities $(\mathrm{p}<0.01)$.

\section{DISCUSSION}

We have demonstrated that the PTP differed significantly between two ventilatory modes used during the weaning process. SIMV was examined as it was routinely employed in our PICU and used, by the majority, but not all, of the UK PICUs we surveyed. ${ }^{4}$ This bias may reflect the results of a randomised trial, ${ }^{6}$ albeit carried out in neonates, which demonstrated that weaning by triggered ventilation compared to intermittent mandatory ventilation was significantly shorter. CPAP was examined as the other weaning mode because, regardless of which ventilatory technique is used initially, neonates and children are often transferred to endotracheal CPAP prior to extubation.

The order in which the two ventilatory modes were investigated was not randomised, but reflected a common pattern of use in clinical practice. SIMV was the standard weaning mode on the PICU, and was always examined first. The children were studied on CPAP after they had stabilised. Thus, it seems unlikely that other factors influenced our results, and that support by CPAP rather than SIMV is associated with a significantly increased PTP. Children with a variety of diagnoses were included in the study, and thus we feel our results are generalisable to other PICUs.

Weaning is likely to be unsuccessful in children with a poor respiratory drive, impaired respiratory muscle function, or a high load on their inspiratory muscles. ${ }^{1}$ The ventilatory mode that minimised the load on the inspiratory muscles, maximising respiratory muscle endurance, would thus seem desirable during weaning. Respiratory muscle endurance depends on both the pressure generated and the duration of the contraction in relation to the cycle duration. ${ }^{7}$ Although we did not measure 
work rate ${ }^{8}$ our finding that SIMV compared to CPAP was associated with a significantly lower PTP suggests it would be the more efficacious weaning mode. No such comparison has been made with long term outcomes in children. In a neonatal trial, ${ }^{9}$ however, weaning by SIMV, when the reduction in the number of supported breaths meant an increasing proportion of the time spent on CPAP was associated with significantly longer weaning time than when weaning was undertaken by patient triggered ventilation. During patient triggered ventilation, the majority of spontaneous breaths were pressure supported. Extrapolating from the present results, an explanation for that finding ${ }^{9}$ was that the work of breathing was likely to be lower in the PTV group, hence they had a shorter duration of weaning.

We conclude that the pressure time product is significantly higher in children when supported by CPAP compared to support by SIMV. These findings should further discourage nursing children on prolonged periods of endotracheal CPAP prior to extubation.
Dr Manczur was supported by the Joint Research Committee of the King's Healthcare NHS Trust. We thank Ms Sue Williams for secretarial assistance.

1 Khan N, Brown A, Venkataraman ST. Predictors of extubation success and failure in mechanically ventilated infants and children. Crit Care Med 1996;24:1568-79.

2 Baumeister BL, el-Khatib M, Smith PG, Blumer JL. Evaluation of predictors of weaning from mechanical ventilation ation of predictors of weaning from mechanical ventilation

3 Epstein SK, Ciubotaru RL, Wong JB. Effect of failed extubation on the outcome of mechanical ventilation. Chest 1997;112:186-92.

4 Manczur T, Greenough A, Rafferty GF. Survey of current practices of weaning from mechanical ventilation in paediatric intensive care. Br $\mathcal{F}$ Intens Care (in press).

5 Sassoon CS, Light RW, Lodia R, Sieck GC, Mahutte CK. Pressure-time product during continuous positive airway pressure, pressure support ventilation and T-piece during weaning from mechanical ventilation. Am Rev Respir Dis 1991;143:469-75.

6 Chan V, Greenough A. Randomised controlled trial of weaning by patient triggered ventilation or conventional weaning by patient triggered ventilation
ventilation. Eur $\mathcal{F}$ Pediatr 1993;152:51-4.

7 Bellemare F, Grassino A. Effect of pressure and timing of contraction on human diaphragm fatigue. $\mathcal{f}$ Appl Physiol contraction on h

8 Collett PW, Perry C, Engel LA. Pressure-time product, flow, and oxygen cost of resistive breathing in humans. $\mathcal{f} A p p l$ Physiol 1985;58:1263-72.

9 Chan V, Greenough A. Comparison of weaning by patient triggered ventilation or synchronous intermittent mandatory ventilation in preterm infants. Acta Paediatr 1994;83: 335-7.

\section{FETAL AND NEONATAL EDITION}

\section{September 2000 issue}

The following articles-being published in the September 2000 issue of the Fetal and Neonatal edition of the Archives of Disease in Childhood - may be of general interest to paediatricians.

\section{ORIGINAL ARTICLES}

Maturation of primary and permanent teeth in preterm infants

$M C$ Backström, L Aine, R Mäki, A-L Kuusela, H Sievänen, A-M Koivisto, $R-S$ Ikonen, M Mäki

Blood glucose levels in a population of healthy, breast fed, term infants of appropriate size for gestational age

$E$ Hoseth, $A$ foergensen, $F$ Ebbesen, $M$ Moeller

\section{CURRENT TOPIC}

Promising strategems for reducing the burden of neonatal sepsis N Modi, R Carr 